\title{
LA TERMINACIÓN ANTICIPADA DEL PROCESO POR LA DESAPARICIÓN SOBREVENIDA DEL INTERÉS EN EL PROCESO CIVIL CHILENO
}

[The anticipated completion of the process due to supervening interest disappearance at the chilean civil procedure]

\section{Maximiliano SILVA HaNISCH*}

\section{RESUMEN}

1 presente artículo busca examinar si la ocurrencia de hechos que impliquen la satisfacción extrajudicial de la pretensión deducida puede hacer desaparecer el interés procesal, y el efecto que ello tiene en la demanda pendiente. El trabajo se enfoca en una revisión doctrinaria de esta cuestión, analizándose el instituto a la luz de las normas procesales civiles vigentes en nuestro país.

\section{Palabras Claves}

Interés procesal - Satisfacción extraprocesal de la pretensión.

\section{ABSTRACT}

The following article seeks to examine whether the extrajudicial satisfaction of the pretension filed, due to the occurrence of particular facts, might cause the disappearance of procedural interest and its consequent effect for the pending claim. The present paper focuses on a doctrinal review and the analysis of the institute under the procedural rules in force in our country.

\section{KeYwORDS}

Procedural interest - Extrajudicial satisfaction of the pretension.

RECIBIDO el 28 de octubre 2016 y APROBADO el 7 de junio de 2017

* Licenciado en Ciencias Jurídicas por la Pontificia Universidad Católica de Chile. Abogado. Alumno del programa de Doctorado en Derecho de la Universidad de Los Andes. Dirección El Golf 40, piso 13, Las Condes. Correo electrónico mmsilva2h@gmail.com; msilva@prieto.cl. 


\section{INTRODUCCIÓN}

Todo conflicto intersubjetivo de intereses puede desembocar en un juicio, de forma tal que un tercero imparcial tenga que decidir la controversia $^{1}$. Si bien lo normal es que los conflictos sean resueltos mediante un pronunciamiento de fondo, también pueden verificarse formas anómalas e extinción de la litis, en virtud de las cuales el proceso termina de forma diferente, sin sentencia que resuelva la controversia.

La terminación anormal del proceso que se estudiará se basa en la desaparición del interés procesal, cuestión que se verifica al cambiar el sustrato fáctico del proceso en curso, y que lleva a cuestionar la necesidad del proceso pendiente.

Como es evidente, los juicios tienen su causa mediata en la prohibición de la autotutela. Y su causa inmediata está en la intención del actor de conseguir aquello que, o su contraparte no le concede voluntariamente, o no puede lograr sino recurriendo al tribunal para lograr el cambio deseado en la realidad jurídica. De esta forma quien demanda tiene necesidad de la actividad jurisdiccional que se desarrolla por medio del proceso, y que obliga al interesado a conseguir el bien reclamado a través de los tribunales de justicia ${ }^{2}$. De esta necesidad nace un interés distinto del interés material que se ventilará como controversia de fondo, siendo secundario e instrumental ${ }^{3}$.

Este es el interés en el proceso mismo, por lo que se denomina procesal ${ }^{4}$, y en otras palabras es la respuesta a por qué el actor pide una determinada tutela frente al demandado 5 .

Pero el sustrato fáctico que condiciona la necesidad del proceso puede cambiar, ya antes que la demanda sea deducida o mientras pende el jui-

1 Carnelutti, Francesco, Instituciones del proceso civil (traducción de la quinta edición italiana por Santiago Sentis Melendo, Buenos Aires, Ediciones Jurídicas Europa-América, 1960, tomo I, p. 28.

2 Chiovenda, Giuseppe, Instituciones de derecho procesal civil (traducción española de la tercera edición italiana, México D.F., Cárdenas Editor y Distribuidor, 1989, tomo I, p. 212.

${ }^{3}$ Carnelutti, Francesco, cit. (n. 1), tomo I, p. 516.

${ }^{4}$ Liebman, Enrico Tullio, Manual de derecho procesal civil (traducción de la quinta edición italiana por Santiago Sentis Melendo, Buenos Aires, Ediciones Jurídicas Europa-América, 1980), p. 115; GASCÓN InCHAUSTI, Fernando considera a este interés como condición de la acción, sin perjuicio de que estimamos que tal elemento integra la pretensión misma. GASCÓN INCHAUSTI, Fernando, La terminación anticipada del proceso por desaparición sobrevenida del interés (Madrid, Civitas, 2003), p. 27.

${ }^{5}$ Gascón Inchausti, Fernando, cit. (n. 4), p. 28. 
cio. En el primer caso existirá una abstención del potencial demandante a actuar, pues no iniciará un juicio que no le satisface ninguna necesidad, y la segunda hipótesis será el objeto de nuestro estudio, analizándose qué ocurre con el juicio cuando el actor satisface su pretensión fuera del proceso, dejando éste de reportarle beneficio. Esta cuestión plantea interesantes problemas en torno a la forma de alegarlo, su naturaleza jurídica, el efecto de cosa juzgada, etc., y estimamos que puede dársele aplicación en el proceso civil, en virtud de un incidente innominado de terminación anticipada del proceso por desaparición sobrevenida del interés.

\section{ACCiÓn, PRETEnsión y DEMANDA}

\section{La relación entre el derecho de acción, la pretensión y la demanda}

La sinonimia entre los conceptos de acción y pretensión ha provocado una grave confusión de ideas ${ }^{6}$, desembocando en una hipertrofia procesal ${ }^{7}$. Esto ha permitido calificar al derecho de acción-cuyo desarrollo dogmático ha sido el más intenso- como un concepto de irrelevancia práctica ${ }^{8}$.

En lo que resulta pertinente para esta investigación adherimos a la teoría abstracta atenuada, que es una vertiente de la teoría abstracta común del derecho de acción' . Esta derivación se concibe a partir de la necesidad de encontrar un nexo que vincule al derecho de acción con el derecho subjetivo

${ }^{6}$ Couture, Eduardo José, Fundamentos del derecho procesal civil (Buenos Aires, Euros Editores S.R.L., 2010), p. 55.

7 Hoyos Henrechson, Francisco, Temas fundamentales de derecho procesal (Santiago, Editorial Jurídica de Chile, 1987), p. 94.

${ }^{8}$ Allorio, Enrico, Problemas de derecho procesal (traducción de Santiago Sentis Melendo, Buenos Aires, Ediciones Jurídicas Europa-América, 1963), tomo I, p. 117; BETHMANN-HOLLWEG califica a este elemento como "indeterminado e infecundo". Chiovenda, Giuseppe, La acción en el sistema de los derechos (Santiago, Editorial Jurídica de Chile, 1992), p. 24.

9 Entre otros autores, adhieren a la teoría abstracta atenuada GUASP, Jaime y Aragoneses, Pedro, Derecho procesal civil (Madrid, Civitas, 2004), pp. 260 y ss.; y Liebman, Enrico Tullio, cit. (n. 4), pp. 111 y ss. La teoría abstracta clásica concibe al derecho de acción como un derecho político que tiene todo ciudadano para poner en movimiento la actividad jurisdiccional. Sobre ella trata CouTure, Eduardo José, cit. (n. 6), pp. 61 y ss., entre muchos otros. Disentimos de la teoría abstracta clásica pues estimamos -siguiendo a GUASP y ARAGONESES, Derecho procesal, cit. (n. 9)-, que "no ofrece sino la exasperación de las tesis privatistas con la vuelta a las doctrinas unitarias en su forma de identificación de derechos o de justificación de derechos o la radicalización de la tesis publicista, hablando, v gr., de la acción como del ejercicio por un particular de funciones públicas". GUASP y ARAGONESES, Derecho procesal, cit. (n. 9), p. 263. 
deducido en juicio, es decir busca un lazo entre la necesidad de recabar de los tribunales su funcionamiento y el derecho que se alega lesionado ${ }^{10}$.

Este vínculo es la afirmación por parte del actor de estar asistido de un derecho subjetivo material que fundamenta su pretensión ${ }^{11}$, sin que sea necesario que sea efectivamente el titular de dicho derecho, siendo suficiente su afirmación para que la pretensión interpuesta se acoja a tramitación y merezca ser fallada ${ }^{12}$. Así, bajo este entendimiento se impone la carga de afirmar la existencia de ciertos hechos o requisitos, cuestión que es distinta de la efectiva correlación entre lo afirmado, lo acreditado en juicio y lo jurídicamente procedente ${ }^{13}$.

Estimamos que esta afirmación que vincula el derecho de acción y la pretensión no es un innecesario desdoblamiento en busca de un tercer elemento entre el derecho material y el procesal ${ }^{14}$. Este vínculo es necesario para encauzar a la acción -un mero poder de obrar abstracto- con una tutela específica que se requiere, evitando así la disociación absoluta entre el puro poder político de obrar, que es previo a la actividad procesal (e incluso está fuera del mundo procesal), y la tutela específica reclamada, que tiene un contenido fáctico concreto ${ }^{15}$. Esto permite distinguir claramente los elementos que componen cada uno de estos conceptos, evitando que uno u otro absorba todo el sustrato conceptual, como una disociación absoluta podría permitirlo.

Dado lo expuesto, nuestra adhesión a la teoría abstracta atenuada nos obliga a excluir del derecho de acción cualquier elemento que no tenga por exclusiva finalidad el sólo requerimiento de la actividad jurisdiccional para reclamar de ella una tutela, por lo que entendemos que está constituido sólo por aquellos elementos indispensables para que un ciudadano pueda excitar la actividad judicial, afirmando asistirle algún derecho.

${ }^{10}$ Hoyos Henrechson, Francisco, cit. (n. 7), p. 124.

11 Ídem.

12 Romero Seguel, Alejandro, La acumulación inicial de acciones (artículos 17 y 18 del código de Procedimiento Civil) (Santiago, Editorial Jurídica Conosur Ltda., 2000), p. 112.

Tal como señala Hunter Ampuero, Iván, "cuando el ciudadano pretende un efecto jurídico afirma la existencia de unos hechos que integran el presupuesto de la norma que fundamenta y hace posible este efecto”. HunTer AMPUERo, Iván, El poder del juez para rechazar in limine la demanda por manifiesta falta de fundamento, en Revista Ius et Praxis, Año 15 (2009), N² 80.

13 Entre nosotros el art. 254 del CPC exige esta cuestión, por lo que nuestro ordenamiento jurídico procesal civil adhiere a esta tesis. Hoyos Henrechson, Francisco, cit. (n. 7), p. 124.

${ }^{14}$ Couture, Eduardo José, cit. (n. 6), p. 61.

15 Guasp Delgado, Jaime, La pretensión procesal (Madrid, Civitas, 1985), p. 49. 
Sobre la pretensión estimamos que es una solicitud en cuanto declaración petitoria, construida en torno a un determinado bien de la vida que se reclama de otro sujeto ante un órgano jurisdiccional. Es un concepto autónomo, distinto de la mera declaración de voluntad que vierte el contendido del derecho de acción ${ }^{16}$.

Respecto de la demanda, es el vehículo por medio del cual se materializa físicamente el requerimiento de justicia. En ella se vierte el contenido fáctico y jurídico que conocerá el tribunal, y constituirá el soporte material de la alegación que se hace. Es propiamente el escrito que se presenta al tribunal.

La sobredimensión conceptual existente -particularmente respecto del derecho de acción- ha impedido lograr una diferenciación acabada de estos elementos, especialmente de la pretensión. Sin perjuicio de lo señalado y más allá del mérito de las distintas clasificaciones que puedan hacer los autores, estimamos que muchos de los elementos que se consideran dentro del derecho de acción en realidad forman parte de la pretensión, dado que -en atención a la adhesión profesada-, no pueden constituir elementos de dicho poder las consideraciones específicas ni los extremos fácticos de la materia respecto de la cual se demanda, los que reservamos para la pretensión.

\section{La pretensión y sus elementos ${ }^{17}$}

Ya delimitada la pretensión de conceptos afines debemos analizar directamente esta figura. Tomando en cuenta lo ya señalado por Guasp y siguiendo también a De la Oliva ${ }^{18}$, entendemos que la esencia de la

${ }^{16}$ GuasP Delgado, Jaime, La pretensión, cit. (n. 15), p. 84. Cabe señalar que disentimos de Guasp y Aragoneses, Derecho procesal, cit. (n. 9) en lo relativo a los requisitos de la pretensión (p. 269) y su contenido (p. 271), pues estimamos que le da una dimensión excesiva, incorporando en ellos elementos que pertenecen a otros conceptos procesales.

17 Sobre la pretensión -y particularmente sobre el derecho de acción- existen múltiples clasificaciones (casi tantas como autores), que pueden agruparse según la mayor o menor relevancia que se le dé a la pretensión, y de acuerdo a la concepción abstracta, abstracta atenuada o concreta que se tenga respecto del derecho de acción. Así, algunos clasifican las condiciones generales de la sentencia estimatoria (Chiovenda, Giuseppe, Instituciones, cit. [n. 2], tomo I, p. 205), otros los requisitos constitutivos de la acción (CAlamandreI, Piero, Instituciones de derecho procesal civil [traducción de la segunda edición italiana y estudio preliminar por Santiago Sentis Melendo, Buenos Aires, Ediciones Jurídicas Europa-América, 1962], p. 256), otros los elementos de la pretensión (FAIRÉn GuILlÉn, Víctor, Teoría general del derecho procesal [México D.F., Instituto de Investigaciones Jurídicas, 1992], p. 85), otros las condiciones de la acción (Liebman, Enrico Tullio, cit. [n. 4], p. 114), etc.

${ }^{18}$ De La Oliva Santos, Andrés, Objeto del proceso y cosa juzgada en el proceso 
pretensión es un requerimiento que hace un determinado sujeto para que se le conceda -por las razones que invoca-, algo respecto de otro sujeto.

Sus elementos identificadores son las partes que intervienen, una determinada petición y el fundamento en virtud del cual ello se pide ${ }^{19}$. A tales elementos agregamos el interés procesal, que es la necesidad que se tiene de la actividad jurisdiccional para la adecuada protección que se requiere ${ }^{20}$.

Así entendida la pretensión, es lo que mantiene funcionalmente con vida al proceso $^{21}$, y constituye además su objeto ${ }^{22}$. Al desaparecer la pre-

civil (Navarra, Aranzadi, 2005), p. 28. Sin perjuicio de no compartir íntegramente su concepción sobre esta cuestión, estimamos correcta la clasificación y posterior análisis que hace sobre la pretensión. Sobre su concepción del derecho de acción y pretensión, véase De La Oliva Santos, Andrés; Díez-Picazo Giménez, Ignacio; Vegas Torres, Jaime, Curso de derecho procesal civil, I, parte general (Madrid, Centro de Estudios Ramón Areces, 2012), pp. 325 y ss.

${ }_{19}$ Respecto de la petición o petitum que se somete al conocimiento del tribunal estamos con Cordón Moreno, Faustino, quien señala que "el petitum no se identifica exclusivamente por el bien pretendido, sino por la concurrencia del bien jurídico y de la forma de tutela que respecto de él se pretende. De esta forma, acciones ejercitadas sobre bienes distintos son igualmente distintas, aunque la tutela jurídica pretendida sea la misma; y acciones que pretenden una tutela distinta son, por lo mismo, diferentes, aunque recaigan sobre un mismo bien”. CORdÓn MORENO, Faustino, Apuntes de derecho procesal civil I (Pamplona, Newbook Ediciones, 1996), p. 108.

Sobre el fundamento de lo pedido como elemento integrante de la pretensión seguimos lo señalado por ROMERo Rodríguez, Sophía, quien refiriéndose a si el elemento jurídico forma o no parte de la causa de pedir señala que la clave es evaluar "si la relación jurídica implicada forma o no parte de la causa de pedir de la acción. Si ello es así, no será lo mismo invocar la propiedad en un caso o el contrato en otro, estando así ante dos acciones distintas. Si ello no es efectivo, si sólo los hechos son los que identifican a la acción, estaremos ante una misma acción sin ser relevante si se arguye el dominio o el derecho personal emanado del contrato". Romero RodríguEZ, Sophía, Concurso de normas y concurso de acciones en el derecho procesal civil chileno, en Revista Ius et Praxis, Año 19 (2013), No 2, p. 225.

${ }^{20}$ Gascón InChausti, Fernando, cit. (n. 4), p. 26. Este autor adhiere a una concepción concreta del derecho de acción, estimando que pertenecen a él -junto al interés-, el derecho subjetivo, la legitimación y la accionabilidad (pp. 22 y ss.). Estimamos que los elementos referidos pertenecen a otros conceptos procesales.

${ }^{21}$ Guasp Delgado, Jaime, La pretensión, cit., (n. 15), p. 85.

22 De La Oliva Santos, Andrés, Objeto, cit. (n. 18), p. 27. De acuerdo a lo señalado por GuASP Delgado, Jaime, La pretensión, "la pretensión procesal es, pues, un acto procesal y al mismo tiempo el objeto del proceso, integrando este objeto, no en cuanto acción que se realiza en un cierto momento, sino en cuanto acto ya realizado que, por ese mismo carácter de estado que imprime a la realidad una vez que ha influido sobre ella, hace girar en torno a sí misma el resto de los elementos 
tensión -por verse afectado alguno de sus elementos-, el proceso queda sin razón de $\operatorname{ser}^{23}$.

\section{El interés procesal}

El interés procesal o interés secundario es uno de los elementos que concebimos dentro de la pretensión. Estimamos que no puede pertenecer al derecho de acción pues agotándose éste con su ejercicio al excitar la actividad jurisdiccional (sin siquiera ser relevante si se da o no curso a la demanda), el interés procesal subsiste durante la tramitación del juicio, y no se agota sino una vez compuesto el litigio ${ }^{24}$.

Como señala Liebman, "el interés para accionar está dado por la relación jurídica entre la situación antijurídica que se denuncia y la providencia que se pide para ponerle remedio mediante la aplicación del derecho, y esta relación debe consistir en la utilidad de la providencia, como medio para adquirir por parte del interés lesionado la protección acordada por el Derecho" ${ }^{25}$. Como señalamos, este interés es lo que motiva al actor a deducir el juicio y a instar a su prosecución, y que subyace a un determinado sustrato fáctico ${ }^{26}$.

que aparecen en la institución procesal”. GuASP Delgado, Jaime, La pretensión, cit. (n. 15), p. 66.

Por su parte, Cortez Matcovich, Gonzalo conceptualiza esta figura como "la petición fundada que se dirige a un órgano jurisdiccional, frente a otra persona, sobre un bien determinado. Se trata por consiguiente, de una declaración de voluntad petitoria”. Bordalí Salamanca, Andrés; Cortez Matcovich, Gonzalo; Palomo VélEz, Diego, Proceso civil. El juicio ordinario de mayor cuantía, procedimiento sumario y tutela cautelar (Santiago, Legal Publishing, 2014), p. 127.

Sobre las teorías de la substanciación e individualización del objeto del proceso, véase Hunter Ampuero, Iván, El poder, cit. (n. 12), pp. 51-54.

${ }^{23}$ La pretensión engendra un proceso en términos tales que sin pretensión el proceso mismo debe ser eliminado, pues queda sin razón de ser. GUASP y ARAGONESES, Derecho procesal, cit. (n. 9), p. 279.

${ }^{24}$ Hoyos Henrechson, Francisco, cit. (n. 7), p. 134.

${ }^{25}$ Liebman, Enrico Tullio, cit. (n. 4), p. 116.

${ }^{26}$ Liebman, Enrico Tullio, cit. (n. 4), p. 396; Chiovenda, Giuseppe, Principios, señala que "el interés en obrar no consiste únicamente en el interés en conseguir el bien garantizado por la ley (esto constituye el contenido del derecho), sino el interés en conseguirlo mediante los órganos jurisdiccionales". CHIOvendA, Giuseppe, Principios de Derecho Procesal Civil (Madrid, Editorial Reus S.A., 1922), p. 182; JORQUera LorCA, René lo denomina como "el interés en la intervención judicial", entendiéndolo como la necesidad de la intervención de los órganos jurisdiccionales para evitar un perjuicio para el actor, de forma tal que la aceptación de la demanda que interpone le reporte alguna utilidad. Jorquera LorCa, René, Sintesis de Derecho Procesal Civil (Santiago, Ediciones Jurídicas La Ley, 1992), p. 33; Para NúŃEZ Ojeda, Raúl y Pérez Ragone, Álvaro, este elemento constituye la necesidad de 
Este elemento es sumamente particular, pues teniendo un origen extraprocesal -la necesidad de obtener aquellos efectos jurídicos que sólo nacerán al ser obtenidos por medio del proceso-, una vez iniciado el pleito pasa a ser parte integrante y esencial de la pretensión ${ }^{27}$.

Así, el interés procesal existe antes de darse inicio al juicio, lo que se verifica en la necesidad de ese futuro proceso, ya sea como la única forma que tiene el actor de doblegar la resistencia del tercero a su solicitud -la subordinación del interés ajeno al propio ${ }^{28}$-, o como el único camino para lograr ciertas autorizaciones judiciales o modificaciones en el modo de ser de las relaciones jurídicas ${ }^{29}$. Y ya en juicio, este interés pasa a ser la fuerza motriz que pone en movimiento al proceso y lo mantiene con vida, desapareciendo al resolverse el conflicto o lograr la autorización o declaración requerida ${ }^{30}$.

Este interés procesal es el mismo antes y durante el juicio, con la diferencia que en el primer caso es lo que motiva al actor a darle inicio, y durante el juicio es lo que impulsa al proceso a seguir adelante y conseguir su fin por medio de la resolución definitiva. Este interés lo presume la ley ${ }^{31}$, pues si no existe interés procesal no puede existir proceso ${ }^{32}$, y se entiende afirmado, existente y actual, de igual manera que los demás elementos que componen la pretensión.

Como se señaló, el interés procesal es tributario de la situación de hecho subyacente al juicio, por lo que es sensible a los cambios en dichas circunstancias, ya sea que se verifiquen antes de su inicio o durante su tramitación.

En el primer caso, la desaparición de este interés procesal haría desapa-

la intervención jurisdiccional para obtener un bien jurídico, donde la pretensión planteada por la parte debe satisfacerse por medio de una respuesta jurisdiccional. Núnez Ojeda, Raúl y Pérez Ragone, Álvaro, Manual de Derecho Procesal Civil, Parte General (Santiago, Legal Publishing, 2013), p. 168; Sobre el punto HunTER Ampuero, Iván, $E l$ poder, señala que "parece razonable entender que la noción de 'interés' tiene una posición central en la configuración de la acción o pretensión; con ella se quiere aludir a la existencia de una lesión al derecho o interés legítimo y la consecuente necesidad, que emerge de dicha lesión, de obtener una tutela jurisdiccional", aunque disentimos del autor en el sentido que entendemos que si bien el interés procesal emana de la situación de hecho que nace de la lesión del derecho o interés legítimo, lo concebimos como un elemento distinto y conceptualmente independiente. Hunter Ampuero, Iván, El poder, cit. (n. 12), p. 146.

${ }^{27}$ Fairén Guillén, Víctor, cit. (n. 17), p. 84.

${ }^{28}$ Chiovenda, Giuseppe, Instituciones, cit. (n. 17), p. 217.

${ }^{29}$ Chiovenda, Giuseppe, Instituciones, cit. (n. 17), p. 259.

${ }^{30}$ Fairén Guillén, Víctor, cit. (n. 17), p. 171.

31 Allorio, Enrico, cit. (n. 8), tomo II, p. 278.

32 Gascón Inchausti, Fernando, cit. (n. 4), p. 88. 
recer la justificación de deducir la demanda, quitándole al futuro proceso su razón de $\operatorname{ser}^{33}$, como sería el demandar la resolución de un contrato cuando ya antes las partes lo han resuelto. Como la regla general es el libre ejercicio del derecho de acción ${ }^{34}$, y considerando que el juez no puede desestimar $a d$ limine el libelo ${ }^{35}$, el interés procesal que pudiera aducirse en este caso sería inexistente o ilegítimo, lo que redundaría en un uso desviado del proceso, es decir un abuso de los derechos procesales con una intención espuria.

Por otra parte, si se deduce un juicio con un interés procesal legítimo y durante la tramitación del proceso desaparece el sustrato fáctico que justificó tal necesidad -p. e. durante un juicio de interdicción muere quien se pretende declarar interdicto-, cabe preguntarse si debe o no seguir adelante dicho juicio. Desde otro punto de vista, la interrogante es si el pronunciamiento definitivo del tribunal debe circunscribirse exclusivamente a la situación que conformó inicialmente el juicio -fallándose con el sustrato fáctico original-, o si por el contrario deben atenderse los cambios acaecidos en los hechos de la controversia durante su pendencia.

\section{La litispendencia y la necesidad del juicio}

La duración temporal de cualquier juicio es inevitable, y durante este lapso las circunstancias fácticas y jurídicas existentes al momento de proponer la demanda pueden sufrir todo tipo de modificaciones. Si estas alteraciones pudieran influir en el proceso sin limitación la tarea del tribunal se dificultaría enormemente, debiendo hacerse cargo de todos los cambios acaecidos en la disputa, lo que perjudicaría a los justiciables que concurrieron al proceso para resolver sus conflictos al tener que soportar los efectos de la inevitable duración del pleito.

En razón de ello, la mayoría de los ordenamientos jurídicos buscan que la sentencia dictada sea un reflejo de lo que ocurriría si el proceso no requiriera de tiempo, de forma tal que el fallo dictado sea idéntico a aquél que se dictara al instante siguiente de proponerse la demanda.

33 Alcalá-Zamora y Castillo, Niceto, Proceso, autocomposición y autodefensa. Contribución al estudio de los fines del proceso (México D.F., Instituto de Investigaciones Jurídicas, 2000), p. 101.

${ }^{34}$ Sobre este principio señala CHIOvENDA, Giuseppe, Instituciones que es válido "cualquier modo de actuación de la ley (y cualquier medio ejecutivo), que sea prácticamente posible y no sea contrario a una norma general o especial de Derecho, debe considerarse admisible”. ChIOvEndA, Giuseppe, Instituciones, cit. (n. 17), tomo I, p. 54.

35 Romero Seguel, Alejandro, Curso de derecho procesal civil. Los presupuestos procesales relativos al procedimiento (Santiago, Legal Publishing, 2015), tomo III, p. 71. Sobre las implicancias de esta cuestión, véase Hunter Ampuero, Iván, El poder, cit. (n. 12), pp. 117-163. 
Como dictar fallos de forma inmediata es imposible, el ordenamiento jurídico busca evitar que la duración del proceso perjudique a quienes recurren a él. Esto se logra gracias a la litispendencia, que es una ficción cuyos efectos permiten mantener "actual" la demanda hasta que el proceso llegue a su fin, de forma tal que la controversia puesta en conocimiento del tribunal se mantenga fija como una fotografía hasta la dictación del fallo que la resuelva, en términos tales que mientras penda el juicio no se vea alterada la situación fáctica, es decir it lite pendente nibil innovetur ${ }^{36}$.

Pero aplicar esta ficción hasta sus últimas consecuencias puede llevar a resultados indeseados. Siempre debe entenderse como un instrumento que garantice la eficacia del proceso, ayudando a validarlo como la mejor forma de solución de conflictos, por lo que esta ficción es compatible -e incluso deseable- con la repercusión en el proceso de ciertas alteraciones fácticas. De esta forma hay una aparente pugna entre la necesidad de establecer un contenido de hecho estable respecto del cual sentenciar la controversia y la apertura del proceso a la realidad que rodea el pleito. En base a esta disyuntiva (más aparente que real), lo que cabe preguntarse es si el pronunciamiento definitivo debe circunscribirse exclusivamente a la situación que conformó inicialmente el juicio, o si deben atenderse los cambios acaecidos en los hechos que conforman la controversia durante la pendencia del juicio.

En principio el pleito se debe resolver sólo considerando las alegaciones iniciales de las partes, de forma tal que luego de terminado el periodo de discusión sólo pueda rendirse prueba sobre lo planteado, para que con posterioridad el juzgador pueda evaluar si las proposiciones iniciales fueron o no acreditadas y con ello emitir su juicio.

Aun cuando la finalidad última de esta ficción es la eficacia del juicio, permitiendo dar un orden lógico a la discusión (facilitando con ello tanto la labor del juez como de los justiciables), no tendría sentido llevar este efecto de la litispendencia a sus últimas consecuencias si ello conduce a la esterilidad del proceso, que es precisamente lo que quiere evitar.

Por esto se busca no producir una ruptura entre la realidad extraprocesal y los elementos esenciales del juicio, ya que podría redundar en su ineficacia. La ficción de inmutabilidad tendería a que la tutela reclamada no considerara alteraciones a la situación original, pero el devenir de la desaparición de una necesidad real de esta tutela aconseja permitir que la novedad fáctica se manifieste en el proceso, pues de lo contrario la sentencia

${ }^{36}$ Chozas Alonso, José Manuel, La perpetuario iurisdictionis: un efecto procesal de la litispendencia (Granada, Comares, 1995), p. 27. 
podría ser inútil, por lo que la limitación de los efectos de la litispendencia es absolutamente deseable ${ }^{37}$.

Además de ello, en todo juicio está ínsita la necesidad de propender a la paz social -uno de los fines del derecho procesal-, por lo que el Estado tiene interés en que cualquiera sea el conflicto que exista se solucione a la brevedad, pues aun cuando la controversia afecte sólo a particulares existe igualmente una afectación de esta paz social, necesaria para propender al bien común ${ }^{38}$. Así, la necesidad del juicio lleva tanto a la comunidad como a las partes a instar por su veloz término, a efecto de resolver lo antes posible la necesidad insatisfecha que motivó el ejercicio del derecho de acción.

Como se señaló, mientras pende el juicio pueden variar sus circunstancias, por lo que puede desaparecer la necesidad que inicialmente podía prestar el proceso, enfrentándonos a una situación de aparente contradicción: si siguiésemos irrestrictamente los postulados de la litispendencia, todo juicio debiera tener su término en la sentencia definitiva, considerando exclusivamente los factores condicionantes tal como existían al momento de iniciarse la demanda, sin atender eventuales cambios fácticos; pero si evaluamos la utilidad y necesidad del juicio, podemos concluir que no es necesario dictar fallo en todos los casos y bajo todas las circunstancias, pues si la pretensión se satisface el juicio deja de ser necesario, pudiendo abrirse la posibilidad de darle término anticipado.

Aquí no hay una real controversia, pues entendido correctamente el principio it lite pendente nihil innovetur, la litispendencia no se contrapone de forma alguna a la revisión de la necesidad del juicio a la luz de nuevos hechos que incidan en la controversia. Precisamente cuando se satisface la pretensión fuera del proceso no es necesario seguir adelante con el jui-

${ }^{37}$ Málaga Diéguez, Francisco La litispendencia (Barcelona, José María Bosch Editores, 1999), pp. 45-47. El autor pone como ejemplos la transmisión de la cosa litigiosa o la muerte de una de las partes ocurrida durante el pleito, que de ocurrir y no reflejarse en el proceso llevarían a una sentencia parcial o ineficaz, que no respondería a los intereses de los justiciables, o iniciado un juicio de incapacitación para enajenar la persona fallece.

38 De acuerdo a Fairén Guillén, Víctor, "bajo la capa de 'acción' hay dos intereses: $1^{\circ} \mathrm{el}$-supuesto, aparente- del actor frente al sujeto pasivo; y $2^{\circ}$, el existente entre el ciudadano 'actor', decidido quizás a resolver el conflicto por medio de la autodefensa, expeditamente, y la comunidad, decidida a que el primer conflicto se resuelva pacíficamente. (...). Mas una vez puesta en actuación, actividad, la función procesal, el interés del particular queda desplazado a un segundo lugar, y puede ocurrir perfectamente que de la 'acción' provenga una resolución contraria al mismo, lo cual sucederá cuando tal interés sea antijurídico o menos protegible que del sujeto pasivo. Y en todo caso, pasa a estar en primer término el interés de la comunidad en que el conflicto se resuelva pacíficamente. FAIRÉN GUILLÉN, Víctor, cit. (n. 17), p. 84. 
cio pendiente, y ello no atenta contra el principio en comento en razón de que la justificación para fijar en un momento el sustrato fáctico de la controversia es la necesidad de este pronunciamiento que recaba el actor, pero cuando el proceso deja de prestar utilidad por haberse satisfecho la necesidad reclamada, este supuesto del que pendía desaparece, de forma tal que no habría razón para no considerar estos cambios. Por esto no se restringirían los efectos de la litispendencia, sino que se les daría un correcto entendimiento.

\section{El interés procesal según la tutela jurídica demandada ${ }^{39}$}

En general en cada tipo de tutela va implícito el interés procesal, pues esta necesidad ya ha sido supuesta por el legislador al predisponer cada forma específica de protección, y aun cuando en abstracto éste sea uno sólo, para su determinación en concreto se debe atender al tipo de tutela según el petitum demandado ${ }^{40}$.

Si se deduce un proceso de condena, el interés se identifica con la insatisfacción padecida por el demandante desde el momento del incumplimiento.

En los procesos declarativos puros puede no ser tan clara la necesidad, pero se verifica en los perniciosos efectos de la incertidumbre que pueden derivarse de una determinada situación o relación jurídica, por lo que se justifica la declaración de existencia, inexistencia o modo de ser de tal situación, a efecto de eliminar la incerteza.

Respecto de las sentencias constitutivas, en aquellas cuya relación es indisponible (p. e. divorcio), el interés se verifica en la necesidad que la sentencia opere para que se verifique el cambio deseado; y respecto de relaciones disponibles, el interés lo constituye la imposibilidad de efectuarlo por faltar la voluntad de un tercero.

\section{LA DESAPARICIÓN DEL INTERÉS PROCESAL POR LA SATISFACCIÓN EXTRAPROCESAL DE LA PRETENSIÓN}

\section{Delimitando la satisfacción extraprocesal de la pretensión}

La satisfacción extraprocesal de la pretensión se verifica al conseguir -fuera de la órbita del juicio-, un resultado práctico equivalente al que se obtendría de una sentencia que acogiera la demanda deducida. En otras

39 La exposición de esta clasificación en GASCÓN InCHAUSTI, Fernando, cit. (n. 4), pp. 32-33.

${ }^{40}$ Allorio, Enrico, cit. (n. 8), tomo II, p. 278. 
palabras, la parte recibe por otra vía lo que pretendía obtener por medio de la jurisdicción.

Para estimar lo anterior no se debe contrastar el hecho verificado de forma estricta con la pretensión deducida en el libelo, sino que respecto del derecho o interés material lesionado. Esto ocurre "cuando se logra el cambio en la realidad al que (el actor) aspiraba cuando acudió a los tribunales, (de forma tal que) como consecuencia del hecho o circunstancias sobrevenida, al actor le deviene innecesario todo proceso, no sólo el de declaración pendiente, sino también uno eventual de ejecución" ${ }^{41}$, de forma tal que el cambio en la realidad debe necesariamente provocar la desaparición de cualquier utilidad lícita que el proceso pueda prestar al actor.

Si ello no ocurre y el proceso sigue siendo tan necesario para el actor como antes del cambio en las circunstancias, la pretensión simplemente no fue satisfecha, por lo que no sería admisible la terminación anticipada del proceso en curso.

\section{Cuándo se verifica}

La satisfacción extraprocesal de la pretensión se verifica cuando el demandado obtiene fuera del proceso en curso el resultado material al que aspiraba con la tutela reclamada. Aun cuando existan varias hipótesis al respecto, siempre se basa en una misma cuestión, consistente en que fuera del proceso pero durante su tramitación se verifica un hecho que conlleva la extinción del interés procesal, en términos tales que para el actor el proceso ya no puede otorgarle la utilidad que inicialmente pretendía.

Respecto de este cambio en la realidad, es irrelevante que sea propiciado por el actor o por el demandado, y es igualmente irrelevante si tal cambio fue voluntario o si se verificó por la ocurrencia de un caso fortuito. Lo esencial es que la pretensión sea satisfecha, lo cual depende directamente del tipo de tutela requerida, pues de ésta emana una determinada y específica manifestación del interés procesal.

\section{Efectos de la desaparición del interés procesal}

Cualquiera sea la forma en la que se satisfaga extraprocesalmente la pretensión y desaparezca sobrevenidamente el interés, estimamos que no puede justificarse la continuación de dicho juicio, pues la fuerza que puso en movimiento al proceso ya no existe ${ }^{42}$. Formalmente puede seguirse con el litigio e incluso puede llegar a fallarse (acogiendo o rechazando la demanda), pero ello carecerá de sentido pues la verdadera finalidad del

\footnotetext{
${ }^{41}$ Gascón InChausti, Fernando, cit. (n. 4), p. 114.

${ }^{42}$ Carnelutti, Francesco, cit. (n. 1), tomo II, p. 171.
} 
interés procesal como elemento integrante de la pretensión es evitar tutelas innecesarias.

Estimamos que en estos casos debe darse término anticipado al proceso pues su prosecución sería inútil, dado que no es un fin en sí mismo, sino una forma de solucionar las controversias que se verifican en la sociedad ${ }^{43}$. Si pendiendo un juicio el actor ve por otro medio satisfecha la necesidad que buscaba entonces ya no se justifica su continuación, pues en definitiva devino en innecesario, inútil e inconducente.

\section{La satisfacción de la pretensión depende del tipo de tutela reclamada}

El cambio en la realidad que satisface el objeto pedido hace desaparecer el interés en el proceso pendiente, siendo necesario revisar cada tipo de tutela a efecto de conocer concretamente cómo el interés que ahí existía desaparece ${ }^{44}$.

En los procesos de condena la satisfacción de la pretensión sólo puede verificarse si se satisface íntegramente la prestación reclamada. Si es el pago de dinero, que el monto sea íntegramente satisfecho; si es la realización de una obra, que ella sea llevada a cabo, etc. (art. 1568 y 1569 del Código Civil).

Respecto de los procesos declarativos la satisfacción extraprocesal de la pretensión pasa por declarar "la existencia, la inexistencia o el modo de ser de un determinado derecho o de una cierta relación jurídica (p. e. que existe una servidumbre constituida sobre una concreta finca, o que tal servidumbre no existe) ${ }^{\prime 4}$. En estos casos la satisfacción extraprocesal exige que el actor no solo obtenga exactamente el mismo resultado que podría obtener por medio de la sentencia, sino que el mismo beneficio que obtendría con la ejecución íntegra del fallo.

En cuanto a los procesos constitutivos, en aquellas hipótesis en las que se requiere expresamente la autorización del tribunal -p. e. sentencia de divorcio- no puede verificarse una satisfacción extraprocesal de la pretensión. En cuanto aquellas deducidas por la falta de concurrencia de la voluntad de una contraparte, la satisfacción extraprocesal puede verificarse si durante el pleito la parte que en un comienzo era reacia manifiesta luego una voluntad concordante con lo reclamado por el actor (p. e. si durante el juicio el demandado accede a suscribir el instrumento al que se comprometió), de forma tal que se logre por anuencia de voluntades lo que demandó por vía jurisdiccional.

43 Carnelutti, Francesco, cit. (n. 1), tomo II, p. 172.

${ }^{44}$ Gascón InChausti, Fernando, cit. (n. 4), p. 116.

45 De La Oliva Santos, Andrés y Fernández, Miguel Ángel, Derecho Procesal Civil (Madrid, Centro de Estudios Ramón Areces, 1992), tomo II, p. 29. 
5. Existe una afectación directa sobre el petitum de la pretensión, lo que extingue el interés

Uno de los elementos integrantes de la pretensión es la concreta y determinada petición que se hace, es decir el cambio en la realidad que se requiere sobre determinado bien de la vida, cuestión que determina la clase de tutela jurídica que solicita el actor.

Es precisamente este elemento el afectado por el cambio en la realidad, pues en definitiva lo que se quería obtener a través del juicio se obtuvo fuera de él. Y para comprobar esta cuestión se debe confrontar la consecuencia práctica de este cambio fáctico y lo requerido en el petitum, de tal forma que el interés procesal se extingue si el cambio en la realidad permite al actor obtener lo que quería.

En la hipótesis planteada sólo se ve afectado el petitum. Los demás elementos que incluimos dentro de la pretensión -los sujetos y la justificación dada para pedir lo reclamado- se mantienen inalterados, pues no son afectados por el cambio en la realidad.

6. La justificación de la terminación anticipada del proceso por la satisfacción extraprocesal de la pretensión

Concebir un proceso desvinculado absolutamente de la realidad sobre la que se proyecta, ignorando las consecuencias que para el juicio tendría el acaecimiento de determinados hechos no parece adecuado para una ley procesal, más aun considerando que tal cuestión no atenta contra el correcto entendimiento de la litispendencia.

La devenida inutilidad del proceso pendiente es lo que justifica -para las partes del juicio- su terminación anticipada. $\mathrm{Al}$ actor ya no le interesará seguir adelante con el proceso si su pretensión se vio satisfecha fuera de él; y el demandado normalmente preferirá dar término inmediato al juicio sin fallo sobre el fondo de la controversia, pues equivaldrá a una sentencia absolutoria.

No es correcto mirar esta cuestión como una manifestación del principio dispositivo que informa el procedimiento, pues "por mucho que en ciertos supuestos las circunstancias o el hecho sobrevenido dependan de la voluntad de las partes, lo cierto es que sólo tendrán relevancia (...) si efectivamente producen como resultado la desaparición del interés, que es cuestión distinta del hecho o circunstancia en sí, y que ya no depende de la voluntad de las partes, sino que de la realidad de las cosas"46. Y una vez verificada esta circunstancia queda al sentenciador, de forma exclusiva y

${ }^{46}$ Gascón Inchausti, Fernando, cit. (n. 4), p. 97. 
excluyente, determinar sus efectos, sobre lo cual la voluntad de las partes carece de relevancia.

La justificación última de este instituto es el orden público, pues como obviamente sólo deben destinarse recursos a fallar controversias reales, seguir adelante con una pretensión carente de interés para el actor es contrario a este orden pues implicará seguir un proceso que es totalmente innecesario.

Cuestión distinta es la que se da en el caso que tanto demandante como demandado de común acuerdo aleguen la desaparición del interés procesal. En dicho caso no es la disposición que se haga sobre la pretensión lo que vincula al tribunal, sino la imposibilidad de éste para cuestionar esa desaparición por el efecto vinculante que tiene para el juez dicha convención probatoria. En este punto se evidencia claramente que el Estado no tiene más interés en resolver la controversia planteada que aquél que puedan tener las propias partes del juicio, por lo que no quedaría más alternativa al sentenciador que tener por cierta la desaparición del interés procesal bajo estas circunstancias, dando así término anticipado al juicio.

De esta forma, son consideraciones que van más allá del pleito específico entre privados las que determinan el término anticipado del proceso, cuestión que si bien puede ser difícil de percibir en el caso concreto son fácilmente constatables al rever al proceso como un medio que el ordenamiento jurídico pone a disposición de los justiciables para solucionar los conflictos y propender al bien común.

\section{La alegación de la desaparición del interés procesal}

La ley presume en abstracto el interés procesal en cada tipo de tutela reclamada ${ }^{47}$, entendiéndolo afirmado, cierto y actual al proponer la demanda, por lo que se debe denunciar que ello ya no es así para que se evalúe la utilidad y necesidad del proceso pendiente.

Siendo una cuestión accesoria a la discusión de fondo, la alegación de la desaparición del interés procesal debe ser planteada al tribunal y debidamente acreditada, pues en definitiva se discute si el juicio ha devenido o no en innecesario.

La forma de evaluar esta cuestión es analizando aisladamente el interés, separándolo de los demás elementos de la pretensión, y revisar cómo este nuevo hecho afecta el petitum. Para ello los extremos fácticos de la controversia -independientemente si la alegación la hace el actor o el demandado- se deben considerar como acreditados (una ficción para el sólo

${ }^{47}$ Allorio, Enrico, cit. (n. 8), tomo II, p. 278. 
efecto de revisar esta cuestión), rindiéndose prueba exclusivamente sobre la veracidad del nuevo hecho alegado.

La incidencia de esta cuestión en la pretensión es una consideración privativa del tribunal, quien debe decidir si tiene o no la aptitud necesaria para que la tutela originalmente requerida devengue en innecesaria, resolviendo si debe terminar anticipadamente el juicio o no.

El estimar como acreditados los demás elementos de la pretensión no implica un prejuzgamiento de la cuestión principal, sino una concesión momentánea para resolver adecuadamente esta cuestión, pues así se permite aislar adecuadamente el interés procesal y evaluar si el nuevo hecho alegado implica o no su desaparición, facilitando el análisis que debe hacerse.

\section{Algunas proyecciones de la satisfacción extraprocesal de la pretensión}

Revisaremos a continuación algunas proyecciones en las que se satisface extraprocesalmente la pretensión y desaparece el interés procesal:

a) En caso que se demande la disolución de -p. e.- una sociedad de responsabilidad limitada, el juicio se fallará acogiendo o desestimando la demanda según los hechos alegados y acreditados, y los fundamentos de derecho que el tribunal estime aplicables al caso.

Pero si la disolución de la sociedad se verifica por cualquier razón durante la pendencia del juicio (p. e., se cumple el plazo pactado para su duración ${ }^{48}$ ), existirá una satisfacción de la pretensión del actor pero verificada fuera del proceso, y sin que éste haya tenido injerencia en ello.

En caso de ocurrir lo anterior, cualquiera de las partes podría alegar este nuevo hecho, y dada su incidencia sustancial en el juicio -pues su verificación afectaría directamente el petitum demandado-, sería necesario comprobar la efectividad de esta proposición para posteriormente evaluar si la pretensión deducida se ve afectada por el acaecimiento de este nuevo hecho.

En este caso el tribunal debe contrastar lo efectivamente requerido por el actor con el nuevo hecho verificado, y evaluar si lo pretendido se ha

48 Art. 2 de la ley 3.918 sobre sociedades de responsabilidad limitada: Las sociedades con responsabilidad limitada, sean civiles o comerciales, se constituirán por escritura pública que contendrá, además de las enunciaciones que expresa el artículo 352 del Código de Comercio, la declaración de que la responsabilidad personal de los socios queda limitada a sus aportes o a la suma que a más de esto se indique.

Estas sociedades no podrán tener por objeto negocios bancarios, y el número de sus socios no podrá exceder de cincuenta.

Art. $352 \mathrm{~N}^{\circ} 7$ del Código de Comercio: La escritura social deberá expresar: $7^{\circ} \mathrm{La}$ época en que la sociedad debe principiar y disolverse. 
satisfecho o no. En caso que ello ocurra el proceso pendiente ya no podrá satisfacer ninguna necesidad lícita del actor, por lo que las justificaciones de orden público que inspiran al proceso como forma de solución de controversia desaparecen, de forma tal que no se justificaría seguir adelante con el juicio.

b) Supongamos un juicio de cobro de pesos en el que un tercero -fuera del juicio- paga al actor lo que éste estima que el deudor le debe: aquí el interés del actor desaparece por cuanto lo pedido en la demanda le fue satisfecho, sin ser relevante para estos efectos que haya sido el demandado quien pagó.

Aun cuando la pretensión deducida sea integrada por los sujetos de la relación material que se discute, es irrelevante que quien satisfaga la pretensión no sea parte material de esta relación, pues ese hecho afectaría al petitum en términos tales que el resultado práctico que el actor pretendía con el juicio se verificaría fuera de él, haciendo innecesario continuar el proceso. Lo relevante es que la pretensión sea satisfecha, no quien la satisfaga, cuestión que tiene correspondencia con la norma sustantiva, pues el epígrafe segundo del Título XIV del Libro IV del Código Civil (en más "CC") razona de igual manera.

En estos casos cualquiera puede pagar al supuesto acreedor, y con ello satisfaría extraprocesalmente la pretensión deducida haciendo desaparecer el interés procesal, sin perjuicio de la eventual subrogación que pueda verificarse entre quien paga y el demandado, de acuerdo a lo dispuesto en los art. 1572, 1573 y 1608 y siguientes del CC.

Sobre este punto el art. 1574 del CC contiene una regla interesante, pues discurre sobre la base de que el pago realizado extinguió la obligación -con lo que desaparece el interés procesal y no podría seguir adelante la pretensión deducida, lo que se verificaría aun cuando el tercero que pagó no pueda a su vez demandar el reembolso al deudor ni retractarse del pago realizado, lo que reafirma el entendimiento de que lo relevante en este punto es la satisfacción de la pretensión, no quien lo haga ni las consecuencias jurídicas que pueda tener ${ }^{49}$.

c) Por último, un ejemplo de satisfacción extraprocesal por caso fortuito se verifica si se demanda la destrucción de un muro erigido en contravención a una obligación de no hacer (art. 1555 del CC), y durante la pendencia del juicio un terremoto lo derriba ${ }^{50}$. En este caso la condena

49 Art. 1574 del CC: El que paga contra la voluntad del deudor, no tiene derecho para que el deudor le reembolse lo pagado; a no ser que el acreedor le ceda voluntariamente su acción.

${ }^{50}$ Art. 1555 del CC: Toda obligación de no hacer una cosa se resuelve en la de indemnizar los perjuicios, si el deudor contraviene y no puede deshacerse lo hecho. 
pretendida por el actor se vería satisfecha gracias al acaecimiento de un hecho fortuito, lo que haría innecesario seguir adelante con el juicio.

\section{EL RECONOCIMIENTO DEL INTERÉS PROCESAL EN EL} CÓDIGO DE PROCEDIMIENTO CIVIL CHILENO

En nuestro Código de Procedimiento Civil (en más "CPC") no existe norma alguna que haga referencia expresa al interés necesario para deducir una pretensión en juicio, sino que la lógica procedimental se basa en la necesidad del pronunciamiento jurisdiccional, y en razón de ello se recurre a la jurisdicción ${ }^{51}$.

Cuando se presenta la demanda no existe una revisión por parte del tribunal del interés procesal al darle curso, sino que la ley sólo contempla un control formal del libelo pretensor (art. 256 del CPC), que es incluso menor que aquél que puede hacer el contradictor en virtud de las excepciones dilatorias del art. 303 del CPC.

Durante la sustanciación del juicio la normativa procedimental no otorga expresamente una instancia que permita cuestionar o denunciar la desaparición de este interés procesal. Y tampoco en la dictación de la sentencia definitiva la ley exige hacer alguna referencia a esta cuestión, ni menos ponderarla en su decisión, sino que sólo se impone al sentenciador la enunciación breve de las peticiones o acciones deducidas en el juicio (art. $170 \mathrm{~N}^{\circ} 2$ del CPC y $\mathrm{N}^{\circ} 2 \mathrm{y} \mathrm{N}^{\circ} 11$ del auto acordado sobre la forma de las sentencias de 30 de septiembre de 1920), donde se subentiende la existencia de este interés procesal.

Por lo tanto, desde la presentación de la demanda, durante la tramitación del juicio y hasta la dictación de la sentencia se entiende que este interés procesal existe, está afirmado y es actual.

Así, la regulación procedimental asume en todo momento que el juicio pendiente es necesario para el actor y el interés procesal se mantiene, tal como existía desde la proposición de la demanda. Pero la revisión de la

Pudiendo destruirse la cosa hecha, y siendo su destrucción necesaria para el objeto que se tuvo en mira al tiempo de celebrar el contrato, será el deudor obligado a ella, o autorizado el acreedor para que la lleve a efecto a expensas del deudor.

Si dicho objeto puede obtenerse cumplidamente por otros medios, en este caso será oído el deudor que se allane a prestarlo.

El acreedor quedará de todos modos indemne.

51 Esto se evidencia en el art. 290 del CPC: "Para asegurar el resultado de la acción, puede el demandante...”. Sin perjuicio del uso equívoco de la voz "acción”, es claro que el legislador pretende un determinado resultado con el juicio, subentendiéndose un interés en él, que busca asegurarlo por medio de las medidas cautelares ahí referidas. 
necesidad del juicio no es algo que pueda escapar al espíritu del CPC, pues considerando que el fin mediato del proceso es propender a la paz social, y su fin inmediato es la resolución de un conflicto específico entre las partes, lo lógico es que sólo aquellos juicios que sean necesarios para los intervinientes y para la sociedad en relación a estos fines se resuelvan por medio de la sentencia definitiva, de forma tal que aun cuando nada se señale explícitamente al respecto, el interés procesal es un elemento que necesariamente debe estar contemplado, y por ello debe poder ser revisado.

De lo que se ha investigado no se ha encontrado ninguna norma en nuestro ordenamiento jurídico civil que haga referencia expresa al interés procesal al momento de deducir una demanda, o que lo exija como impulso procesal mientras penda el juicio. Sin perjuicio de ello, estimamos que esta cuestión tiene asidero en nuestro ordenamiento jurídico y puede ser revisada a la luz de principios procesales, siendo esto suficiente para darle cabida.

\section{Los hechos del pleito y el art. 321 del CPC}

En virtud del principio de preclusión una etapa procesal sucede a la otra. Luego de terminado el periodo de discusión la controversia ya está íntegramente planteada (contenida principalmente en la demanda y la contestación, sin perjuicio de lo dispuesto en el art. 312 del CPC), pasándose luego a la etapa de prueba en la que se acreditarán los extremos fácticos de la petición deducida y las defensas opuestas, para luego fallar conforme al mérito de las probanzas rendidas y las consideraciones jurídicas que el tribunal estime aplicables a la especie.

Excepcionalmente el legislador adjetivo permite que formen parte de la controversia principal hechos acaecidos antes o durante la etapa de discusión pero que no fueron alegados por las partes por no haberlos conocido, así como también hechos verificados con posterioridad a dicho estadio procesal pero sustancialmente relacionados con el asunto debatido (art. 321 del $\mathrm{CPC}^{52}$ ).

La desaparición del interés procesal es evidentemente un hecho relacionado con el asunto principal objeto de la litis, de forma tal que verificándose dicho supuesto fáctico podría alegarse y ampliarse la prueba que ha de rendirse dentro del término probatorio a esta cuestión, pero tendría

${ }^{52}$ Art. 321 del CPC: No obstante lo dispuesto en el artículo anterior, es admisible la ampliación de la prueba cuando dentro del término probatorio ocurre algún hecho substancialmente relacionado con el asunto que se ventila.

Será también admisible la ampliación a hechos verificados y no alegados antes de recibirse a prueba la causa, con tal que jure el que los aduce que sólo entonces han llegado a su conocimiento. 
el inconveniente de reservar la declaración de la desaparición del interés procesal para la sentencia definitiva, en circunstancias que -de acogerse la alegación-, su objetivo sería precisamente evitar este pronunciamiento.

El interés procesal no es "la cuestión o asunto que ha sido objeto del juicio" (art. 158 del CPC), sino que es uno de los elementos que integran la pretensión, y al denunciarse su desaparición procede analizarlo aisladamente, por lo que estimamos que no es necesario reservar esta cuestión para la sentencia definitiva.

La conclusión anterior se mantiene aun cuando lo resuelto tenga efectos análogos a una sentencia absolutoria para el demandado, pues el término anticipado del juicio no pasa por una eventual "falta de derecho" del actor, pues no hay un pronunciamiento sobre el fondo del asunto, sino que por la desaparición del interés procesal.

Aun cuando pudiera denunciarse la desaparición sobrevenida del interés procesal ampliando la prueba que debe rendirse en virtud del art. $321 \mathrm{del}$ CPC, nada obstaría plantearlo de forma accesoria e independiente, dada la amplitud de la cuestión incidental contenida en el CPC y por el hecho que de acogerse terminaría anticipadamente el proceso, razón por la cual no existirá un pronunciamiento sobre el objeto del pleito.

\section{La cuestión incidental en el CPC}

En toda contienda civil surgen cuestiones que se someten al conocimiento y fallo del tribunal y que son distintas de la controversia de fondo, respecto de las cuales la ley confiere al tribunal que sustancia el juicio expresa competencia para fallarlas (art. 111 del Código Orgánico de Tribunales y art. 7 del CPC).

Nuestro CPC reguló esta materia dando una normativa general y supletoria (Título IX, Libro I), y una regulación especial respecto de ciertos incidentes (Título X, Libro I) ${ }^{53}$. El art. 82 de la norma adjetiva los define, entendiéndolos como "toda cuestión accesoria de un juicio que requiera pronunciamiento especial" ${ }^{54}$.

${ }^{53}$ Una breve reseña histórica de los incidentes en SALAS ViVALDI, Julio E., Los incidentes, $y$ en especial el de nulidad en el proceso civil, penal y laboral (Santiago, Editorial Jurídica de Chile, 2000), pp. 15-22.

${ }^{54}$ Respecto de las distintas posturas doctrinarias relativas a si es de la esencia de los incidentes su tramitación con audiencia de las partes, véase SALAS VIVALDI, Julio E., cit. (n. 53), pp. 28-31; Anabalón SAnderson, Carlos, Tratado práctico de derecho procesal chileno. Disposiciones comunes a todo procedimiento y de las cuestiones de competencia, (Santiago, Librotec Limitada, 1966), tomo II, pp. 10-11; CASARINO Viterbo, Mario, Manual de derecho procesal, Derecho Procesal Civil (Santiago, Editorial Jurídica, 2005), p. 147. 
Esta definición es distinta de la contenida en el Proyecto de Código de Procedimiento Civil elaborado por Vargas Fontecilla y Lira, pues fue modificada por distintas comisiones. El proyecto concebía a los incidentes como "toda cuestión subalterna que se suscite entre las partes durante el curso del juicio, i cuya resolución influya más o menos directa i eficazmente en el éxito de la cuestión principal".

Analizando el proyecto, la primera comisión revisora (1874 a 1884) aceptó la definición, pero suprimió una parte ("i cuya resolución influya más o menos directa i eficazmente en el éxito de la cuestión principal”), con lo que se previno un entendimiento inexacto, evitando toda posibilidad de prejuzgamiento. Esta definición fue nuevamente modificada por la segunda comisión (1886 a 1892), eliminando el carácter "subalterno" con que se concibió a los incidentes, evitando rebajarlos a cuestiones de importancia menor dentro del juicio y adoptando su texto actual ${ }^{55}$.

Gracias a las modificaciones introducidas por las sucesivas revisiones se amplió el concepto original de incidente. Sus requisitos esenciales son: $1^{\circ}$ que lo planteado sea accesorio a la cuestión principal; $2^{\circ}$ que entre ambas cuestiones (principal y accesoria) exista una conexión; y $3^{\circ}$ que la cuestión deducida incidentalmente exija un pronunciamiento especial del tribunal ${ }^{56}$. Así entendido, el incidente es una pretensión independiente y distinta del objeto del juicio, que requiere un pronunciamiento especial ${ }^{57}$.

En virtud de lo anterior estimamos que podría alegarse incidentalmente la desaparición sobrevenida del interés procesal, pues cumpliría con todas las exigencias para ser considerada una alegación incidental de acuerdo al tenor de la normativa contenida en el CPC y el entendimiento que le ha dado la doctrina. Esta alegación tendría una evidente conexión con lo principal (se revisaría si el interés procesal contenido en la pretensión principal fue satisfecho); exigiría un pronunciamiento especial (que resuelva si este interés procesal ha desaparecido, evitando continuar el juicio); y la cuestión planteada no versaría sobre el objeto del juicio (sino que sobre uno de los elementos de la pretensión individualmente considerado, por lo que no constituiría un prejuzgamiento).

55 Toro Melo, David; Echeverría i reyes, Aníbal, Código de Procedimiento Civil anotado por David Toro Melo i Aníbal Echeverría i Reyes (Santiago, Imprenta, Litografía i encuadernación Barcelona, 1902), p. 144.

56 Anabalón Sanderson, Carlos, cit. (n. 54), p. 8.

57 Pfeiffer Richter, Alfredo Óscar, Apuntes de derecho procesal del profesor Pfeiffer. Procedimiento ordinario de mayor cuantía e incidentes (Santiago, Autoeditor, 1998), tomo III, p. 167. 


\section{El incidente de terminación anticipada del juicio}

Como se señaló, el texto legal procesal no reconoce expresamente la posibilidad de denunciar la desaparición sobrevenida del interés, aunque es manifiesto que bajo su lógica sólo pueden admitirse procesos que satisfagan necesidades actuales y reales por medio de la pretensión deducida. Admitir la continuación de procesos que devinieron en innecesarios es un abuso del ejercicio del derecho de acción, y además un atentado a los fines mismos del proceso.

Por otra parte, la norma adjetiva no restringe ni en su letra ni en su espíritu la proposición de un incidente con tales características, además que el término de un proceso sin una sentencia definitiva no es novedoso bajo el texto y la lógica del CPC, por lo que si se admite una terminación anticipada como sanción -en el abandono del procedimiento-, con mayor razón debe admitirse una terminación anticipada cuando el proceso no presta utilidad alguna, sin necesidad de dictar una sentencia definitiva.

En el aspecto procedimental, la alegación de la desaparición del interés procesal en un determinado caso debe cumplir con todos los requisitos de tramitación de los incidentes ordinarios, tanto en lo relativo a la oportunidad para deducirlos (art. 84 inc. $2^{\circ}, 85$ inc. $1^{\circ}$ y 86 del CPC), la recepción de la prueba en caso que el tribunal lo estime necesario (art. 89 y 90 del CPC) y su fallo (art. 91 del CPC).

Además de lo anterior, se deben tener en consideración las siguientes cuestiones:

Es un incidente de previo y especial pronunciamiento

Este tipo de incidentes impiden que la causa principal siga sustanciándose hasta que se resuelva la alegación planteada, tal como señala el art. 87 del CPC. La norma no indica qué necesita un incidente para tener este efecto, pero de los casos regulados en este cuerpo adjetivo se desprende que debe existir una afectación al correcto desenvolvimiento del proceso, sin que haya un pronunciamiento sobre el fondo del asunto ${ }^{58}$.

Alegar la falta de necesidad sobrevenida de un juicio pendiente por la satisfacción extraprocesal de la pretensión impediría avanzar la cuestión principal, pues sería precisamente la necesidad de dicho pronunciamiento el que se pondría en entredicho, por lo que la alegación incidental tendría esta característica.

La resolución que resuelve el incidente tiene la naturaleza jurídica de una sentencia interlocutoria de primer grado

${ }^{58}$ Las excepciones dilatorias (art. 303 del CPC), la acumulación de autos (art. 92 y ss. del CPC) y el abandono del procedimiento (art. 152 y ss. del CPC) tienen en común una afectación del procedimiento mismo, sin pronunciarse sobre el objeto de la controversia. 
Respecto del tipo de resolución que fallaría este incidente según la clasificación del art. 158 del CPC -cuestión sumamente relevante para conocer el régimen recursivo aplicable-, ya descartamos a las sentencias definitivas pues aquí no hay pronunciamiento sobre la cuestión o asunto que ha sido objeto del juicio. Igualmente podemos descartar a los decretos, providencias o proveídos, pues ellos no resuelven un incidente.

Entonces nos queda dilucidar si la resolución que acoge este incidente es un auto o una sentencia interlocutoria.

De la clasificación de las sentencias interlocutorias que hace el art. 158 del CPC $^{59}$, podemos descartar las denominadas de segundo grado (que sirven de base al pronunciamiento de una sentencia definitiva), pues el incidente precisamente evita un pronunciamiento sobre el objeto del juicio. Cabe entonces dilucidar si la resolución es de aquellas que establecen o no derechos permanentes en favor de las partes, y sobre el punto seguimos la tesis que entiende estos derechos como aquellos que subsistentes en el tiempo y que superviven al juicio donde nacen, de forma tal que su existencia no se agota al término de dicho proceso $^{60}$.

Estimamos que el término anticipado de un juicio por la desaparición del interés procesal que le dio origen y justificó su prosecución es un derecho procesal permanente para ambas partes, pues impide seguir adelante con la tramitación del juicio. Es análogo al derecho procesal que tiene el demandado en caso que se declare el abandono del procedimiento, impidiendo al actor seguir con la tramitación del juicio, pero en este caso el mismo derecho asiste a ambas partes, pues cualquiera de ellas puede solicitar la terminación anticipada.

\section{La desaparición sobrevenida del interés en segunda instancia}

Todo lo que se ha dicho se ha referido -al menos implícitamente- a un cambio sobrevenido en las circunstancias fácticas existentes durante la tramitación del juicio en primera o única instancia. Pero ¿qué ocurre si hay una afectación del interés procesal una vez dictada la sentencia de grado y estando pendiente algún recurso?

El hecho que se haya dictado sentencia estimativa o denegatoria de la demanda no cambia las conclusiones que se han venido dando. Conceptualmente la situación es exactamente la misma, se haya o no dictado

59 Art. 158 inc. 3 del CPC: Es sentencia interlocutoria la que falla un incidente del juicio, estableciendo derechos permanentes a favor de las partes, o resuelve sobre algún trámite que debe servir de base en el pronunciamiento de una sentencia definitiva o interlocutoria.

60 Oliver Calderón, Guillermo, Sentencia interlocutoria y derechos permanentes (Santiago, Jurídica ConoSur, 1997), p. 62. 
sentencia, pero sus efectos son peculiares pues obliga a tomar en consideración que ya hubo un pronunciamiento sobre la cuestión objeto del juicio, en términos tales que el fallo de segunda instancia resuelve si debe o no mantenerse la sentencia dictada, sin perjuicio que todo lo que se pide en fase de apelación está condicionado por la pretensión de la instancia, estando por ello íntimamente ligada a la impugnación ${ }^{61}$.

Como la situación es la misma se deben mantener los criterios ya referidos.

Debe existir una solicitud incidental de alguna de las partes en orden a solicitar la terminación anticipada del proceso por la desaparición sobrevenida del interés. La tramitación de esta cuestión se regulará por el art. 220 del $\mathrm{CPC}^{62}$, que dispone que la alegación accesoria que se deduzca puede tramitarse como incidente, por lo que estimamos que la eventual prueba que haya que rendirse se regirá por el art. 90 del CPC y no por el art. 207 del mismo Código, en atención a que la última regla versa sobre la prueba de la cuestión principal, por lo que no debiera aplicarse a este incidente la restricción probatoria de segunda instancia, debiendo regirse por la regla general de los incidentes. Por último, de lo resuelto no podría deducirse recurso de apelación, según el art. 210 de la norma adjetiva.

En lo demás, los efectos de acoger el incidente de terminación anticipada del proceso por desaparición sobrevenida del interés en primera o segunda instancia serán exactamente los mismos.

\section{La declaración de la desaparición del interés procesal de oficio por parte del tribunal}

Lo que nos resta por revisar es si puede o no el sentenciador hacer presente a los justiciables una posible desaparición del interés procesal. Es

${ }^{61}$ De acuerdo a GaScón InCHAusti, Fernando, "Aquello sobre lo que versa el proceso en estas fases posteriores al dictado de la primera sentencia no es tanto si debe concederse al actor la tutela pedida en la demanda, cuanto si la sentencia impugnada es conforme a Derecho. Ahora bien, esta actividad jurisdiccional ha de llevarse a cabo siempre a la luz de las pretensiones y contra pretensiones inicialmente ejercidas por los litigantes. Precisamente por esto último es correcto entender que la acción afirmada sigue integrando el objeto del proceso, y el punto de referencia de cuanto en él han de decir el tribunal y las partes: en efecto, todo lo que en fase de recurso se pide del tribunal viene mediatizado por la acción ejercitada en la primera instancia y por la relación que guarda con esa acción el contenido de la sentencia impugnada". GASCÓN INCHAUSTI, Fernando, cit. (n. 4), p. 258.

${ }^{62}$ Art. 220 del CPC: Las cuestiones accesorias que se susciten en el curso de la apelación, se fallarán de plano por el tribunal, o se tramitarán como incidentes. En este último caso, podrá también el tribunal fallarlas en cuenta u ordenar que se traigan en relación los autos para resolver. 
decir, si se requiere una alegación específica sobre este punto por alguna de las partes o si por el contrario puede el tribunal de oficio estimar afectado o desaparecido el interés procesal del actor.

Aun cuando el tribunal llegue a la convicción de la desaparición del interés procesal, ya sea con la prueba rendida por las partes o aquella que ordene agregar de oficio según el art. 159 del CPC, estimamos que no podría dar término anticipado al juicio, sino que sólo podría reservar esta declaración para la sentencia definitiva, rechazando la demanda por esta razón.

El principio dispositivo que empapa la norma adjetiva impide por regla general la actividad jurisdiccional por iniciativa del sentenciador, lo que también se aplica a la tramitación del proceso. En base a ello y siendo excepcional que el tribunal esté facultado para referirse sobre la pretensión en un momento anterior a la sentencia definitiva (p. e. art. 256 del CPC), y no existiendo texto expreso que le mande o permita proceder de oficio en esta materia -según el decir del art. 160 del CPC-, estimamos que no podría el tribunal declarar de oficio la desaparición del interés procesal.

Sin perjuicio de lo señalado, en caso que el tribunal estime que pudo haber desaparecido este interés procesal podría decretar alguna de las medidas para mejor resolver para esclarecer esta cuestión (art. 159 del CPC), particularmente las de los numerales $1^{\circ}$ y $2^{\circ}$, que tienen por objeto expreso recabar antecedentes para "esclarecer el derecho de los litigantes" y aclarar "aquello que considera de influencia en la cuestión", ambas cuestiones que engloban sin dificultad una eventual desaparición sobrevenida del interés procesal.

\section{Las consecuencias del incidente}

La hipótesis planteada se refiere a la satisfacción de la pretensión -que es lo querido por el demandante-, cuestión que se verifica durante el proceso pero sin que éste haya tenido incidencia en ello. En principio el actor habrá obtenido el bien de la vida que quería pero por un medio distinto de la vía jurisdiccional, de forma tal que ya estando satisfecho el actor, el juicio pendiente no podrá reportarle ninguna utilidad lícita.

Como se señaló, el incidente se debe acoger o rechazar según si el nuevo hecho afecta o no la tutela jurisdiccional demandada. Si se rechaza, el juicio sigue adelante y termina la ficción de tener por acreditados los demás elementos necesarios de la pretensión, lo que implica que el actor deberá probar fehacientemente los extremos fácticos de su demanda. Si se acoge el incidente, se declarará que desapareció el motor que hacía avanzar el proceso, razón por la que se le debe dar término anticipado al juicio.

Así, acogiéndose el incidente se verificarían las siguientes consecuencias: 
a) Equivale a una sentencia absolutoria. Luego de desaparecido el interés procesal, el juicio pendiente deviene en inútil e innecesario, por lo que debe terminar sin un pronunciamiento sobre el fondo de la controversia. En este caso la resolución que pone término al juicio tiene efectos análogos a una sentencia absolutoria, aunque sin serlo. No es sentencia absolutoria precisamente porque no resuelve el fondo de la controversia -no se pronuncia sobre si el actor tenía o no razón-, pero impide que el demandante obtenga lo pretendido en el juicio y que el demandado sea condenado a ello, so pena que el actor vea satisfecha doblemente su pretensión o se dicte un pronunciamiento absolutamente inútil.

En el ejemplo iii) del acápite 8 del capítulo III, no tiene sentido dictar una sentencia condenatoria si la pared cuya destrucción se demandó se desploma durante el transcurso del juicio. Es inoficioso sentenciar que la pared debe ser destruida si ello ya ocurrió, así lo alegó una parte y así le consta al tribunal.

Según hemos señalado, en estos casos debe terminar anticipadamente el juicio y simplemente dejar constancia que lo pretendido ya fue obtenido fuera del proceso. Con esto no se condena al demandado, equivaliendo a su respecto a una sentencia absolutoria.

b) Efecto negativo y positivo de la cosa juzgada. En caso que el tribunal declare terminado un proceso pendiente por la desaparición sobrevenida del interés procesal, no habrá un pronunciamiento sobre el fondo de la controversia.

Aun cuando esto ocurra, estimamos que igualmente puede verificarse el efecto negativo de la cosa juzgada (art. 175 del CPC), para evitar que se presente una nueva demanda invocando el mismo interés procesal que ya se declaró desaparecido, pues -recordemos- lo pretendido en el proceso previo ya fue obtenido fuera de él, de forma tal que se debe evitar una doble satisfacción del bien de la vida reclamado.

La excepción de cosa juzgada tendrá efectos limitados, pues el análisis se centrará principalmente en el contraste entre el petitum de la nueva demanda y el hecho acaecido durante el anterior juicio -que significó su terminación anticipada-, de forma tal que si lo demandado en el segundo juicio es el mismo beneficio jurídico que fue satisfecho extraprocesalmente durante la pendencia del primero -y que reiteramos significó su terminación anticipada-, estimamos que cabe acoger la excepción de cosa juzgada (art. 177 del CPC), sin ser relevante los argumentos dados en uno u otro, siendo aplicable la máxima de que la cosa juzgada abarca "lo deducido y lo deducible" ${ }^{\prime 3}$.

${ }^{63}$ Romero Seguel, Alejandro, La cosa juzgada en el proceso civil chileno, doctrina 
Sin perjuicio de lo señalado, esta excepción de cosa juzgada que puede oponerse es restringida, en razón que no procedería si se verifica un nuevo interés procesal -o renace el que desapareció-, siempre que tenga la aptitud necesaria para dar nuevamente inicio al juicio. La supervivencia del interés procesal se verifica si, en el ejemplo del punto iii) del acápite 8 del capítulo III, la sociedad de responsabilidad limitada en definitiva no se disolvió por la expiración del plazo, y sin perjuicio de ello se dio término anticipado al primer juicio, en cuyo caso podría deducirse un nuevo juicio sobre esta cuestión al haber renacido para el actor el interés procesal. Pero si se mantiene la misma situación fáctica que justificó darle término anticipado al primer juicio debe acogerse la excepción de cosa juzgada opuesta ${ }^{64}$.

Por su parte el efecto positivo o prejudicial de la cosa juzgada (servir de base a los tribunales para decidir procesos ulteriores) no podría verificarse en caso de una terminación anticipada del proceso, al no haber fallo sobre el fondo de la controversia. Lo resuelto en virtud del incidente reseñado es una cuestión meramente procesal, sobre si procede o no seguir adelante con el juicio pendiente. No hay una valoración respecto de si lo propuesto tenía o no mérito, sino que el juzgamiento que se haga versará únicamente sobre la incidencia que el hecho nuevo que se alega tenga sobre el interés procesal que motivó el juicio, por lo que esta resolución no puede servir de base para otro pronunciamiento en un juicio distinto.

No podría existir este efecto prejudicial de la cosa juzgada siquiera respecto de la declaración misma de la desaparición sobrevenida del interés, pues ella sólo juzga que en un determinado juicio el interés procesal desapareció. Lo resuelto no podría tener incidencia en otro juicio pues este mismo interés procesal puede renacer, razón por la cual no existe ninguna realidad juzgada de forma inmutable que vaya a servir de base a un futuro pronunciamiento jurisdiccional. A lo más podría invocarse el hecho mismo

y jurisprudencia (Santiago, Editorial Jurídica de Chile, 2002), pp. 68-71.

${ }^{64}$ Esta hipótesis está recogida en la Partida Tercera, Título I, Ley XXIV “Cómo puede la cosa mueble ser demandada otra vez al demandado aunque sea librado de ella por juicio": A veces el juez da por libre al demandado debido a que no tiene la cosa mueble que le demandan, o porque la perdió sin su culpa y sin su engaño; pero si después fallaren que es poseedor de ella no se puede defender el demandado por decir que ya fue liberado de aquella demanda por juicio; porque no se la quitaron en la primera demanda, porque no la podía mostrar, pero si después la cobró de cualquier manera que sea, está obligado de mostrarla como en el primero, porque todo hombre debe entender que el libramiento no fue hecho sino por razón que no la tenía.

Pero si el juez libró por juicio al demandado por que no había derecho ninguno en aquella cosa que demandaba, siempre se puede defender el demandado contra él por razón de aquel juicio, que no está obligado de mostrarla ni de responder por ella al demandante ni a otro que la demande en su nombre. 
del término anticipado del juicio por la desaparición del interés procesal, pero esta invocación sólo podría hacerse en cuanto hecho procesal (lo que ocurriría al hacer presente el abandono del procedimiento de un juicio en otro), pero esta cuestión no tiene relación alguna con la prejudicialidad ${ }^{65}$.

c) No es un equivalente jurisdiccional. En caso de declararse la terminación anticipada del proceso por la desaparición sobrevenida del interés procesal no habría pronunciamiento jurisdiccional sobre el fondo de la controversia planteada. Y la resolución que resuelve esta cuestión incidental tiene exclusivamente efectos procesales, que si bien se asimilan a una sentencia absolutoria no resuelven la controversia dando la razón al demandado, de forma tal que no impide al actor proponer nuevamente la demanda aduciendo un nuevo interés procesal o renovado el primitivo, como se revisó.

En razón de lo expuesto la terminación anticipada del proceso por la desaparición sobrevenida del interés procesal no es un equivalente jurisdiccional.

\section{CONCLUSIONES}

El interés procesal se verifica en la necesidad del interesado en conseguir un bien de la vida, reclamándolo a través de los tribunales de justicia.

Este interés procesal es uno de los elementos que integra la pretensión que se deduce judicialmente, y se sustenta en el sustrato fáctico que subyace al juicio.

Tanto antes como durante la tramitación del proceso pueden cambiar las circunstancias de hecho que motivaron al sujeto a interponer su demanda, afectando este interés procesal. Si estos hechos se verifican antes de deducida la demanda, el potencial demandante no tiene razón para deducir el juicio, y si se verifican durante la tramitación del proceso, se debe revisar la necesidad del proceso.

Si los hechos verificados durante la tramitación del juicio y ajenos a éste implican una satisfacción de la pretensión, se justifica dar término al juicio sin dictar una sentencia definitiva, pues seguir adelante con este juicio sería contrario al orden público, al seguir un proceso innecesario y que podría implicar una doble satisfacción de la demanda.

Aun cuando en nuestro ordenamiento jurídico no está expresamente reconocido este interés procesal, es indudable que la norma adjetiva razona

65 Sobre la prejudicialidad en el proceso civil chileno, ver Romero SEgUeL, Alejandro, La prejudicialidad en el proceso civil, en Revista chilena de Derecho, Volumen 42, N²: pp. 453-482; y Rivero Hurtado, Renée Marlene, La prejudicialidad en el proceso civil chileno (Santiago, Thomson Reuters, 2016). 
sobre la base de que el actor busca satisfacer una determinada necesidad lícita por medio del juicio que deduce, por lo que la verificación de cualquier hecho que afecte lo pedido (el petitum) puede ser alegado durante el juicio, lo que permite revisar la utilidad y necesidad del juicio pendiente.

\section{BIBLIOGRAFÍA}

Alcalá-Zamora y Castillo, Niceto, Proceso, autocomposición y autodefensa. Contribución al estudio de los fines del proceso (México D.F., Instituto de Investigaciones Jurídicas, 2000).

Alfonso el Sabio, Las Siete Partidas de Alfonso el Sabio (Guadalajara, Colegio de Notarios del Estado de Jalisco, 2009).

Allorio, Enrico, Problemas de derecho procesal, tomo I y II (traducción de Santiago Sentis Melendo, Buenos Aires, Ediciones Jurídicas Europa-América, 1963).

Anabalón Sanderson, Carlos, Tratado práctico de derecho procesal chileno. Disposiciones comunes a todo procedimiento y de las cuestiones de competencia, tomo II (Santiago, Librotec Limitada, 1966).

Bordalí Salamanca, Andrés; Cortez Matcovich, Gonzalo; Palomo Vélez, Diego, Proceso civil. El juicio ordinario de mayor cuantía, procedimiento sumario y tutela cautelar (Santiago, Legal Publishing, 2014).

Calamandrei, Piero (1962): Instituciones de derecho procesal civil, tomo I (traducción de la segunda edición italiana y estudio preliminar por Santiago Sentis Melendo, Buenos Aires, Ediciones Jurídicas Europa-América, 1962).

Carnelutti, Francesco, Instituciones del proceso civil, tomos I y II (traducción de la quinta edición italiana por Santiago Sentis Melendo), (Buenos Aires, Ediciones Jurídicas Europa-América, 1960).

Casarino Viterbo, Mario, Manual de derecho procesal. Derecho Procesal Civil tomo III (Santiago, Editorial Jurídica, reimpresión de la sexta edición, 2005).

Chiovenda, Giuseppe, Principio de Derecho Procesal Civil, tomo I (traducción española de la tercera edición italiana, prólogo y notas de José Casáis y Santaló, Madrid, Editorial Reus S.A., 1922).

Chiovenda, Giuseppe, Instituciones de derecho procesal civil, tomos I y II (traducción del italiano y notas de derecho español por E. Gómez Orbaneja, México D.F., Cárdenas Editor y Distribuidor, 1989).

Chiovenda, Giuseppe, La acción en el sistema de los derechos (traducción del italiano por Santiago Sentis Melendo, (Santiago, Editorial Jurídica de Chile, 1922).

Chozas Alonso, José Manuel, La perpetuario iurisdictionis: un efecto procesal de la litispendencia (Granada, Comares, 1995).

Cordón Moreno, Faustino, Apuntes de derecho procesal civil I (Pamplona, Newbook Ediciones, 1996).

Couture, Eduardo José, Fundamentos del derecho procesal civil (Buenos Aires, Euros Editores S.R.L., cuarta reimpresión de la cuarta edición, 2010).

De La Oliva Santos, Andrés; Fernández, Miguel Ángel, Derecho Procesal Civil, tomo II (Madrid, Centro de Estudios Ramón Areces, 1992).

De La Oliva Santos, Andrés, Objeto del proceso y cosa juzgada en el proceso civil (Navarra, Aranzadi, 2005).

De La Oliva Santos, Andrés; Díez-Picazo Giménez, Ignacio; Vegas Torres, Jaime, 
Curso de derecho procesal civil, I, parte general (Madrid, Centro de Estudios Ramón Areces, 2012).

FAIRÉn Guillén, Víctor, Teoría general del derecho procesal (México D.F., Instituto de Investigaciones Jurídicas, 1992).

GASCÓN INCHAUSTI, Fernando, La terminación anticipada del proceso por desaparición sobrevenida del interés (Madrid, Civitas, 2003).

GUASP DELGADO, Jaime, La pretensión procesal (Madrid, Civitas, 1985).

Guasp Delgado, Jaime; Aragoneses, Pedro, Derecho procesal civil, tomo I y II (Madrid, Civitas, 2004).

Hoyos Henrechson, Francisco, Temas fundamentales de derecho procesal (Santiago, Editorial Jurídica de Chile, 1987).

Hunter Ampuero, Iván, El poder del juez para rechazar in limine la demanda por manifiesta falta de fundamento, en Revista Ius et Praxis, Año 15 (2009), № 2: pp. 117-163.

Hunter Ampuero, Iván, La aplicación judicial del derecho en el proceso civil. Doctrina, jurisprudencia y derecho comparado (Santiago, Legal Publishing, 2015).

Jorquera LorCa, René, Sintesis de Derecho Procesal Civil (Santiago, Ediciones Jurídicas La Ley, 1992).

Liebman, Enrico Tullio, Manual de derecho procesal civil (traducción de la quinta edición italiana por Santiago Sentis Melendo, Buenos Aires, Ediciones Jurídicas Europa-América, 1980).

Málaga DiéGuez, Francisco, La litispendencia (Barcelona, José María Bosch Editores, 1999).

Núñez Ojeda, Raúl; Pérez Ragone, Álvaro, Manual de Derecho Procesal Civil, Parte General (Santiago, Legal Publishing, 2013).

Oliver CAlderón, Guillermo, Sentencia interlocutoria y derechos permanentes (Santiago, Jurídica ConoSur, 1997).

Pfeiffer Richter, Alfredo Óscar, Apuntes de derecho procesal del profesor Pfeiffer. Procedimiento ordinario de mayor cuantía e incidentes. Tomo III. (Santiago, Autoeditor, 1998).

Rivero Hurtado, Renée Marlene, La prejudicialidad en el proceso civil chileno (Santiago, Thomson Reuters, 2016).

Romero Rodríguez, Sophía, Concurso de normas y concurso de acciones en el derecho procesal civil chileno, en Revista Ius et Praxis, Año 19 (2013), Nº 2: pp. 207-250.

Romero Seguel, Alejandro, La acumulación inicial de acciones. Artículos 17 y $18 \mathrm{del}$ código de Procedimiento Civil (Santiago, Editorial Jurídica Conosur Ltda., 2000).

Romero Seguel, Alejandro, La cosa juzgada en el proceso civil chileno, doctrina y jurisprudencia (Santiago, Editorial Jurídica de Chile, 2002).

Romero Seguel, Alejandro, Curso de derecho procesal civil. La acción y la protección de los derechos, tomo I (Santiago, Legal Publishing, 2014).

Romero SEguel, Alejandro, Curso de derecho procesal civil. Los presupuestos procesales relativos al procedimiento, tomo III (Santiago, Legal Publishing, 2015).

Romero Seguel, Alejandro, La prejudicialidad en el proceso civil, en Revista chilena de Derecho, Volumen 42 (2015), No 2: pp. 453-482.

Salas Vivaldi, Julio E., Los incidentes, y en especial el de nulidad en el proceso civil, penal y laboral (Santiago, Editorial Jurídica de Chile, 2000).

Toro Melo, David; Echeverría I ReYes, Aníbal, Código de Procedimiento Civil anotado 
por David Toro Melo i Aníbal Echeverría i Reyes (Santiago, Imprenta, Litografía i encuadernación Barcelona, 1902).

\section{NORMAS CITADAS}

Constitución Política de la República de Chile

Código Civil (CC)

Código de Procedimiento Civil (CPC)

Código Orgánico de Tribunales (COT)

Código de Comercio (CCom)

Ley N 3.918, sobre Sociedades de Responsabilidad Limitada 